\title{
Chloroquine Sulfate
}

National Cancer Institute

\section{Source}

National Cancer Institute. Chloroquine Sulfate. NCI Thesaurus. Code C78058.

The sulfate salt of chloroquine, a quinoline compound with antimalarial and antiinflammatory properties. Chloroquine is the most widely used drug against malaria, except for those cases caused by chloroquine resistant Plasmodium falciparum. Although the mechanism of action is not fully understood, chloroquine is shown to inhibit the parasitic enzyme heme polymerase that converts the toxic heme into non-toxic hemazoin, thereby resulting in the accumulation of toxic heme within the parasite. Chloroquine may also interfere with the biosynthesis of nucleic acids. 